\title{
Medicamentos Biológicos e Biossimilares: Descontinuidades no Sistema de Farmacovigilância em Portugal
}

\section{Biologicals and Biosimilars: Gaps in the Pharmacovigilance System in Portugal}

\author{
Maria da Conceição Constantino PORTELA $\otimes^{1}$, Carlos SINOGAS ${ }^{2,3}$, Fernando Albuquerque de ALMEIDA $^{4}$, \\ Ricardo BAPTISTA-LEITE ${ }^{1,5}$, Alexandre CASTRO-CALDAS ${ }^{1}$ \\ Acta Med Port 2017 Mar;30(3):205-212 - https://doi.org/10.20344/amp.8079
}

\section{RESUMO}

Introdução: A monitorização da segurança associada aos medicamentos biológicos e biossimilares exige um sistema de informação alinhado com o enquadramento regulamentar. Tendo em conta que podem ocorrer descontinuidades entre a regulamentação europeia, nacional e a respetiva tradução operacional, importa pesquisar e identificar essas lacunas.

Material e Métodos: Foi desenvolvida uma análise qualitativa dos suportes legais vigentes em julho de 2016 ao nível europeu e nacional, com foco na farmacovigilância. Desta análise decorreu a caracterização operacional do sistema em Portugal.

Resultados: Foram identificadas zonas de descontinuidade no âmbito do sistema de farmacovigilância em Portugal, pela ausência de especificidade para os medicamentos biológicos e biossimilares.

Discussão: A segurança associada à terapêutica biológica apresenta determinantes específicos relacionados com os medicamentos, prescrição e traçabilidade, que não encontram replicação nos outros segmentos do mercado farmacêutico.

Conclusão: Com base nas lacunas identificadas, são apresentadas propostas de intervenção com o objetivo de incrementar a segurança associada à utilização clínica de medicamentos biológicos e biossimilares.

Palavras-chave: Biossimilares; Farmacovigilância; Medicamentos Biológicos; Monitorização de Fármacos; Portugal; Sistemas de Notificação de Reações Adversas a Medicamentos

\section{ABSTRACT}

Introduction: Biological and biosimilar medicinal products have specific characteristics that call for a closer monitoring of their safety profile. Since the current legal framework stems from both European and national regulations, some gaps in the operational field may be expected. The goal of this paper is to identify these gaps and propose changes to the current information systems and pharmacovigilance regulations.

Material and Methods: A qualitative analysis of current pharmacovigilance regulatory framework and supporting information system was conducted.

Results: Current pharmacovigilance system does not seem to vouch for the safe use of biologicals and biosimilar drugs. The gaps found in reviewed materials may be attributable to their lack of specificity for biopharmaceuticals.

Discussion: Biologicals therapy presents specific determinants related with the drugs, prescription, and traceability, without replication in any other segment of the pharmaceutical market. They are able to shape their safety profile.

Conclusion: The existing pharmacovigilance's regulatory framework should be adjusted in order to improve the safety related with biopharmaceutical therapy. Some intervention measures are proposed.

Keywords: Adverse Drug Reaction Reporting Systems; Biological Products; Biosimilar Pharmaceuticals; Drug Monitoring; Pharmacovigilance; Portugal

\section{INTRODUÇÃO}

Os medicamentos biológicos e biossimilares apresentam um elevado grau de complexidade e variabilidade que pode condicionar o respetivo perfil de segurança e/ou de eficácia. Estes fatores devem também ser tomados em consideração em presença de interpermutabilidade e substituição. Assim, é imperativo garantir o acompanhamento do rácio benefício risco, tendo em conta que no alinhamento entre os domínios regulamentar e operacional podem existir fronteiras de descontinuidade instrumental que urge identificar e suprir. Por ser universal, o sistema de farmacovigilância pode não estar a captar a informação específica dos medicamentos biológicos e biossimilares, que aqui se pretende identificar e caracterizar.

\section{MATERIAL E MÉTODOS}

Foi conduzida uma análise qualitativa, com base na legislação publicada a nível nacional e europeu, e nos documentos normativos emitidos pelas autoridades reguladoras. Recorreu-se à informação codificada disponível no sítio eletrónico da autoridade reguladora do medicamento em Portugal (INFARMED), das instituições públicas tuteladas pelo Ministério da Saúde e da Agência Europeia do

\footnotetext{
1. Instituto de Ciências da Saúde. Universidade Católica Portuguesa. Lisboa. Portugal.

2. Acompanhamento Farmacoterapêutico, Lda. Pavia. Portugal.

3. Departamento de Biologia. Escola de Ciências e Tecnologia. Universidade de Évora. Évora. Portugal.

4. Institute of Health Policy \& Management. Erasmus University Rotterdam. Rotterdam. The Netherlands.

5. Faculty of Health, Medicine and Life Sciences. Maastricht University. Maastricht. The Netherlands.

$\bowtie$ Autor correspondente: Maria da Conceição Constantino Portela. mccportela@ics.lisboa.ucp.pt

Recebido: 27 de julho de 2016 - Aceite: 22 de dezembro de 2016 | Copyright @ Ordem dos Médicos 2017
} 
Medicamento. A pesquisa foi restrita à regulamentação vigente no âmbito da farmacovigilância. Numa etapa subsequente, a análise recaiu sobre o conteúdo da mesma, tendo sido selecionada aquela que reporta especificamente aos medicamentos biológicos e biossimilares. Considerou-se, por acréscimo, a regulamentação em áreas convergentes com este domínio: contrafação, rastreabilidade e cuidados de saúde transfronteiriços. Posteriormente foi conduzida uma avaliação destinada a caracterizar globalmente a operacionalização das determinações regulamentares e identificar os fluxos de informação e sistemas de comunicação que são utilizados no âmbito da prescrição e dispensa de medicamentos biológicos e biossimilares, bem como do sistema de notificação e registo de reações adversas, em Portugal. A recolha de informação incidiu sobre a legislação que se encontra em vigor à data de julho de 2016, independentemente do ano em que esta foi publicada.

\section{RESULTADOS}

Os medicamentos biológicos, biotecnológicos e biossimilares

Um medicamento biológico é o que contém uma ou mais substâncias ativas produzidas ou derivadas de uma origem biológica. Os medicamentos biológicos de referência são aprovados com base em documentação técnico-científica completa, nos âmbitos da qualidade, segurança e eficácia. Os medicamentos biossimilares são aprovados por um processo abreviado e que garante a similaridade, mas não a equivalência, ao medicamento de referência pré-existente. Neste contexto, os estudos de comparabilidade permitem gerar a evidência necessária para consubstanciar a similaridade nos domínios da qualidade, segurança e eficácia, garantindo assim que ao medicamento biossimilar é reconhecida a eficácia e segurança identificadas para o medicamento de referência. ${ }^{1}$

São biotecnológicos quando produzidos em fermentador por células usualmente modificadas por tecnologias de DNA recombinante para a expressão da substância ativa. Os medicamentos biológicos podem ser obtidos por via biotecnológica ou por extração de um organismo vivo. No primeiro caso, a produção em biorreactor pode determinar heterogeneidades entre os medicamentos de diferentes fabricantes ou entre vários lotes de um mesmo medicamento que estão na base de reações adversas, enquanto no segundo caso o controlo homeostático individual não faz prever heterogeneidades significativas no âmbito intraindividual, mas antes no interindividual. A sua natureza proteica, o elevado peso molecular e a origem biológica dos materiais usados no seu fabrico, podem determinar uma variabilidade intrínseca suscetível de provocar alterações no perfil de segurança e eficácia que urge acautelar, pelo que este segmento de medicamentos é considerado prioritário em termos de farmacovigilância. ${ }^{2}$

\section{Modelos de acessibilidade à terapêutica}

A receita médica é o instrumento que garante o acesso à terapêutica com medicamentos biológicos, a qual tam- bém pode assumir uma das categorias de receita médica restrita ${ }^{1}$ e neste caso a prescrição e/ou a utilização estão reservadas a certos meios especializados, caracterizados pela vigilância mais próxima do seu perfil de segurança. De uma forma geral podem causar efeitos adversos muito graves e carecem assim de uma vigilância especial durante o tratamento. ${ }^{3}$

\section{O sistema de farmacovigilância e a garantia de segu- rança}

\section{Enquadramento regulamentar}

O sistema de farmacovigilância tem vindo a evoluir de uma abordagem centrada na recolha, análise e resposta às notificações de suspeita de reações adversas,,$^{3,4}$ para uma outra que promove a gestão do risco. Por acréscimo, diferencia segmentos de medicamentos com um perfil de risco acrescido, associado a uma maior incerteza e que carecem de monitorização adicional. ${ }^{5,6}$

Esta postura evolutiva foi destacada pela regulação europeia (Tabela 1) e subsequente transposição (Tabela 2), requerendo uma dinâmica adaptativa dos sistemas de farmacovigilância, "que atenda ao progresso científico e técnico", em ordem à segurança dos medicamentos autorizados. ${ }^{4}$

A notificação espontânea de suspeita de reações adversas é basilar para todo o sistema de farmacovigilância. Para além dos "efeitos nocivos e involuntários resultantes da utilização autorizada de um medicamento em doses normais, (...) também os erros terapêuticos e as utilizações fora dos termos da autorização de introdução no mercado, incluindo a utilização indevida e abusiva do mesmo."2 devem ser consideradas. Por via da transposição, as reações adversas são as que se apresentam como nocivas e não intencionais, a um medicamento. ${ }^{13}$

\section{Prescrição, dispensa e utilização}

O enquadramento regulador (Tabela 3) determina a prescrição obrigatória por via eletrónica, através da denominação comum internacional $(\mathrm{DCl})$ da substância ativa, ${ }^{14}$ e a inclusão do nome de marca ou o do titular de autorização de introdução no mercado. Encontra-se plasmado na legislação o impedimento da substituição do medicamento prescrito por denominação comercial em três situações, ${ }^{3}$ mas não é feita referência explícita aos medicamentos de origem biológica.

Quanto à dispensa ao público, estes medicamentos estão classificados como sujeitos a receita médica, ou a receita médica restrita, sendo os segundos dispensados em regime de ambulatório, através das farmácias hospitalares. ${ }^{15}$ Contudo "os procedimentos quanto ao período de cedência de medicamentos, à informação prestada ao doente, ao registo de informação, às condições em que se procede ao ato de dispensa ou à consulta farmacêutica são muito distintas entre hospitais, o que pode conduzir a variações na acessibilidade e utilização dos medicamentos." 16

A prescrição destes medicamentos está circunscrita aos centros prescritores de agentes biológicos nos casos 
Tabela 1 - Enquadramento legal no domínio da farmacovigilância

\begin{tabular}{|c|c|c|c|}
\hline Diploma & Data & Âmbito & Transposição \\
\hline Diretiva 2001/83/CE & 6 novembro 01 & $\begin{array}{l}\text { Estabelece um código comunitário para os } \\
\text { medicamentos de uso humano }\end{array}$ & $\begin{array}{l}\text { Decreto-lei } n^{\circ} 176 / 2006 \\
\text { de } 30 \text { de agosto }\end{array}$ \\
\hline Diretiva 2004/27/CE & 31 março 04 & $\begin{array}{l}\text { Altera a Diretiva 2001/83/CE que estabelece um } \\
\text { código comunitário relativo aos medicamentos } \\
\text { para uso humano }\end{array}$ & $\begin{array}{l}\text { Decreto-lei } n^{\circ} 176 / 2006 \\
\text { de } 30 \text { de agosto }\end{array}$ \\
\hline Regulamento $726 / 2004^{7}$ & 31 março 04 & $\begin{array}{l}\text { Estabelece procedimentos comunitários de AIM } \\
\text { e fiscalização de medicamentos de uso humano } \\
\text { e veterinário e institui a Agência Europeia do } \\
\text { Medicamento }\end{array}$ & NA \\
\hline Regulamento 1394/2007 & 13 novembro 07 & Medicamentos de terapia avançada & NA \\
\hline Regulamento 1235/2010 & 15 dezembro 10 & Farmacovigilância & NA \\
\hline Diretiva 2010/84/UE & 15 dezembro 10 & $\begin{array}{l}\text { Altera a Diretiva 2001/83/UE no que respeita à } \\
\text { farmacovigilância }\end{array}$ & $\begin{array}{l}\text { Decreto-lei } n^{\circ} 20 / 2013 \\
\text { de } 14 \text { de fevereiro } \\
\text { que procede à sétima } \\
\text { alteração ao Decreto- } \\
\text { Lei } n^{\circ} 176 / 2006 \text { de } 30 \\
\text { de agosto }\end{array}$ \\
\hline Diretiva 2011/62/UE & 8 junho 11 & $\begin{array}{l}\text { Altera a Diretiva 2001/83/UE, para impedir a } \\
\text { introdução na cadeia de abastecimento legal de } \\
\text { medicamentos falsificados }\end{array}$ & $\begin{array}{l}\text { Decreto-lei } n^{\circ} 128 / 2013 \\
\text { de } 5 \text { de setembro }\end{array}$ \\
\hline $\begin{array}{l}\text { Regulamento de Execução } \\
520 / 2012\end{array}$ & 19 junho 12 & $\begin{array}{l}\text { Relativo à realização das atividades de } \\
\text { farmacovigilância previstas no Regulamento (CE) } \\
726 / 2004\end{array}$ & NA \\
\hline Regulamento $1027 / 2012^{8}$ & 25 outubro 12 & $\begin{array}{l}\text { Altera o Regulamento } 726 / 2004 \text { no que diz } \\
\text { respeito à farmacovigilância }\end{array}$ & NA \\
\hline Diretiva 2012/26/UE & 27 outubro 12 & $\begin{array}{l}\text { Altera a Diretiva 2001/83/CE no que diz respeito à } \\
\text { farmacovigilância }\end{array}$ & $\begin{array}{l}\text { Decreto-lei } n^{\circ} 128 / 2013 \\
\text { de } 5 \text { de setembro }\end{array}$ \\
\hline $\begin{array}{l}\text { Regulamento de Execução } \\
\text { 198/2013 }\end{array}$ & 7 março 13 & $\begin{array}{l}\text { Relativo à seleção de um símbolo de identificação } \\
\text { dos medicamentos para uso humano sujeitos a } \\
\text { monitorização adicional. }\end{array}$ & NA \\
\hline Regulamento $357 / 2014^{9}$ & 3 fevereiro 14 & $\begin{array}{l}\text { Completa a Diretiva 2001/83/CE do Parlamento } \\
\text { Europeu e do Conselho e o Regulamento (CE) } \\
726 / 2004 \text { do Parlamento Europeu e do Conselho } \\
\text { no que diz respeito às situações em que podem } \\
\text { ser exigidos estudos de eficácia após autorização }\end{array}$ & NA \\
\hline Regulamento $658 / 2014^{10}$ & 15 maio 14 & $\begin{array}{l}\text { Relativo às taxas cobradas pela Agência Europeia } \\
\text { de Medicamentos pela realização de atividades } \\
\text { de farmacovigilância relativas aos medicamentos } \\
\text { para uso humano }\end{array}$ & NA \\
\hline $\begin{array}{l}\text { Regulamento Delegado } \\
2016 / 161\end{array}$ & 2 outubro 15 & $\begin{array}{l}\text { Estabelece regras para os dispositivos de } \\
\text { segurança que figuram nas embalagens dos } \\
\text { medicamentos para uso humano }\end{array}$ & NA \\
\hline
\end{tabular}

Fonte: Compilação elaborada pelos autores.

NA: Não aplicável.

aplicáveis, ${ }^{17}$ os quais devem proporcionar uma resposta rápida em presença de reações adversas. ${ }^{18}$ Foram instituídos centros de prescrição para a artrite reumatoide, espondilite anquilosante, artrite psoriática, artrite idiopática juvenil poliarticular e psoríase em placas. ${ }^{11}$

Distintamente, o regime de prescrição e dispensa de medicamentos destinados ao tratamento de doentes com doença de Crohn ou colite ulcerosa apenas impõe a prescrição por médicos especialistas em gastrenterologia. A dispensa tem de ocorrer por intermédio dos serviços far- macêuticos hospitalares onde o medicamento é prescrito e a monitorização da utilização destes medicamentos tem uma periodicidade mensal. ${ }^{19}$

As orientações da Comissão Nacional de Farmácia e Terapêutica determinam que a opção deve recair sobre as substâncias ativas que possuam medicamentos biossimilares, sendo dispensado o medicamento mais acessível. ${ }^{20}$ Deve também garantir a utilização de medicamentos com a mesma marca durante o tempo que se revelar necessário para assegurar a rastreabilidade. Em presença de 
alternância entre marcas, deve ser respeitado o princípio de precaução. Com o mesmo objetivo, a alternância entre medicamentos biossimilares deve respeitar um período mínimo de seis meses. Os medicamentos biológicos, fruto do seu perfil de segurança, estão sujeitos a monitorização adicional. ${ }^{21,22}$
A utilização dos medicamentos biológicos em doenças do foro reumático, psoríase e doença inflamatória intestinal foi regulada pela Comissão Nacional de Farmácia e Terapêutica; as Normas de Orientação Clínica da Direção Geral de Saúde (DGS) emitem recomendações de âmbito clínico, ouvidas as sociedades científicas. ${ }^{23}$

Tabela 2 - Enquadramento nacional na área da farmacovigilância e outra legislação aplicável aos medicamentos biológicos e biossimilares

\begin{tabular}{|c|c|c|}
\hline Diploma & Data & Âmbito \\
\hline Decreto-lei n 176/2006 & 30 agosto 06 & Estatuto do medicamento \\
\hline Decreto-lei $n^{\circ} 20 / 2013$ & 14 fevereiro 13 & $\begin{array}{l}\text { Procede à sétima alteração ao Decreto-lei n 176/2006 (Estatuto do } \\
\text { Medicamento) }\end{array}$ \\
\hline Decreto-lei n 128/2013 & 5 setembro 13 & $\begin{array}{l}\text { Transpõe as Diretivas } n^{\circ} 2011 / 62 / E U \text { e } n^{\circ} 2012 / 26 / E U \text { no âmbito dos } \\
\text { medicamentos falsificados e da farmacovigilância; procede à primeira } \\
\text { alteração ao Decreto-lei } n^{\circ} \text { 20/2013, que procede à sétima alteração ao } \\
\text { Decreto-lei } n^{\circ} 176 / 2006\end{array}$ \\
\hline Despacho $n^{\circ} 9767 / 2014$ & 21 julho 14 & $\begin{array}{l}\text { Define as condições de prescrição, dispensa e comparticipação dos } \\
\text { medicamentos destinados ao tratamento de doentes com doença de Crohn } \\
\text { ou colite ulcerosa }\end{array}$ \\
\hline Lei $n^{\circ} 51 / 2014^{11}$ & 25 agosto 14 & Procede à nona alteração ao Decreto-lei n 176/2006 \\
\hline Decreto-lei n 52/2014 & 25 agosto 14 & $\begin{array}{l}\text { Define as normas de acesso e cooperação em cuidados de saúde } \\
\text { transfronteiriços }\end{array}$ \\
\hline Despacho n $11042-F / 2014$ & 29 agosto 14 & $\begin{array}{l}\text { Define o modelo de receita médica para ser dispensada noutro Estado } \\
\text { Membro }\end{array}$ \\
\hline Portaria $n^{\circ} 48 / 2016$ & 22 março 16 & $\begin{array}{l}\text { Define as condições de dispensa e utilização dos medicamentos destinados } \\
\text { ao tratamento de doentes com artrite reumatoide, espondilite anquilosante, } \\
\text { artrite psoriática, artrite idiopática juvenil poliarticular e psoríase em placas }\end{array}$ \\
\hline Portaria $n^{0} 198 / 2016^{12}$ & 20 julho 16 & Procede à alteração do Anexo I da Portaria n 48/2016 \\
\hline
\end{tabular}

Fonte: Compilação elaborada pelos autores.

Tabela 3 - Documentos de caráter normativo no âmbito da prescrição, dispensa e utilização de medicamentos biológicos e biossimilares, em Portugal

\begin{tabular}{|c|c|c|c|}
\hline Documento & Entidade emissora & Data & Âmbito \\
\hline Circular Normativa $n^{\circ} 01 / 2015$ & SPMS & 14 julho 15 & $\begin{array}{l}\text { Metodologia para pedido de dispensa de } \\
\text { obrigatoriedade de aquisição ao abrigo dos } \\
\text { acordos quadro da SPMS, EPE }\end{array}$ \\
\hline $\begin{array}{l}\text { Comissão Nacional de Farmácia e } \\
\text { Terapêutica }\end{array}$ & INFARMED & novembro 15 & $\begin{array}{l}\text { Utilização dos medicamentos biológicos em } \\
\text { doenças reumáticas, psoríase e doença } \\
\text { inflamatória intestinal }\end{array}$ \\
\hline Norma 010/2014 & DGS & 23 julho 14 & Centro prescritor de agentes biológicos \\
\hline $\begin{array}{l}\text { Normas relativas à prescrição de } \\
\text { medicamentos e produtos de saúde }\end{array}$ & $\begin{array}{l}\text { INFARMED } \\
\text { ACSS }\end{array}$ & 29 outubro 15 & $\begin{array}{l}\text { Prescrição de medicamentos e produtos de } \\
\text { saúde }\end{array}$ \\
\hline $\begin{array}{l}\text { Normas relativas à dispensa de } \\
\text { medicamentos e produtos de saúde }\end{array}$ & $\begin{array}{l}\text { INFARMED } \\
\text { ACSS }\end{array}$ & 29 outubro 15 & $\begin{array}{l}\text { Dispensa de medicamentos e produtos de } \\
\text { saúde }\end{array}$ \\
\hline $\begin{array}{l}\text { Utilização dos medicamentos } \\
\text { biológicos em doenças reumáticas, } \\
\text { psoríase e doença inflamatória } \\
\text { intestinal }\end{array}$ & $\begin{array}{l}\text { INFARMED } \\
\text { CNFT }\end{array}$ & novembro 15 & $\begin{array}{l}\text { Utilização dos medicamentos biológicos em } \\
\text { doenças reumáticas, psoríase e doença } \\
\text { inflamatória intestinal }\end{array}$ \\
\hline
\end{tabular}

Fonte: Compilação elaborada pelos autores.

ACSS: Administração Central do Sistema de Saúde; CNFT: Comissão Nacional de Farmácia e Terapêutica; DGS: Direção Geral da Saúde; INFARMED: Autoridade Nacional do Medicamento e Produtos de Saúde; SPMS: Serviços Partilhados do Ministério da Saúde. 
Tabela 4 - Análise comparativa da informação que consta nos impressos do utente e do profissional de saúde em Portugal, no âmbito da notificação de suspeita de reações adversas a medicamentos

\begin{tabular}{lll}
\hline & Impresso de notificação de reações adversas & Doentes \\
\hline Identificação do medicamento & Profissional de saúde & $X$ \\
\hline Nome completo do medicamento & - & - \\
Nome de marca & $X$ & $X$ \\
Forma farmacêutica & - & $X$ \\
Dosagem & $X$ & $X$ \\
No lote & $X$ & $X$ \\
Via de administração & $X$ & $X$ \\
Data em que iniciou o medicamento & $X$ & $X$ \\
Data em que parou de usar o medicamento & $X$ & $X$ \\
Foi a primeira vez que usou o medicamento & - & $X$ \\
Dose diária & $X$ & $X$ \\
Indicação terapêutica & $X$ & $X$ \\
\hline
\end{tabular}

Fonte: Impressos oficiais para notificação de suspeita de reações adversas a medicamentos em Portugal

A aquisição dos medicamentos biológicos e biossimilares pelas entidades do SNS está sujeita às determinações oficiais que vinculam às disposições no âmbito dos acordos quadro. Está prevista a possibilidade de ser invocado um regime de exceção sempre que se trata de assegurar a continuidade da terapêutica e se não estiver provada a respetiva interpermutabilidade. ${ }^{24}$

\section{O fluxo de informação no sistema de farmacovigilância}

A informação sobre segurança dos medicamentos é preferencialmente recolhida através das notificações espontâneas de suspeita de reações adversas, por parte de profissionais de saúde e dos doentes. ${ }^{25}$ Para o efeito, são utilizados impressos específicos disponibilizados pelo INFARMED. ${ }^{26}$ (Tabela 4). A informação é recolhida e encaminhada para os centros regionais de farmacovigilância e para a autoridade competente - INFARMED, sendo centralizada na Agência Europeia do Medicamento através do sistema de informação EudraVigilance.

\section{Rastreabilidade}

As orientações da Comissão Nacional de Farmácia e Terapêutica determinam que deve ser assegurada a rastreabilidade dos medicamentos biológicos e biossimilares. ${ }^{14}$ Nesse sentido, a Direção Geral de Saúde está obrigada a manter um registo de todos os doentes. ${ }^{11}$ Numa fase de transição, até que a DGS tenha o sistema operacional, a informação é centralizada no INFARMED. ${ }^{11}$

Distintamente para os medicamentos e produtos de terapia avançada, a monitorização do risco deve possuir uma conotação abrangente, com rastreabilidade total do doente, do produto, materiais base e matérias-primas, incluindo todas as que entrem em contacto com as células ou tecidos que possa conter, pelo menos durante 30 anos após o termo do prazo de validade do produto. ${ }^{27}$

\section{Implicações decorrentes dos cuidados de saúde trans- fronteiriços}

A mobilidade de doentes em regime transfronteiriço resulta numa prestação de cuidados de saúde extensível ao perímetro de todos os estados-membros ${ }^{28}$ Esta realidade exigiu a definição de medidas para facilitar o reconhecimento mútuo das receitas médicas, tendo sido aprovado o modelo de receita médica para prescrição em Portugal e dispensa num outro estado-membro. ${ }^{29}$ Neste âmbito, a prescrição de medicamentos biológicos é acompanhada pela explicitação da marca comercial. ${ }^{30}$

No domínio do financiamento, que reporta ao estado-membro de afiliação, pode haver no limite um envolvimento de três estados-membros associados à utilização de um medicamento: o de prescrição, o de dispensa e o de financiamento. Neste enquadramento tripartido torna-se ainda mais complexo monitorizar a segurança e assegurar a rastreabilidade da terapêutica.

\section{Questões envolventes à contrafação}

Com o intuito de impedir a entrada de medicamentos falsificados no circuito comercial, foi estabelecida a utilização de um código comunitário para os medicamentos de uso humano. ${ }^{31}$ No direito nacional o Decreto-lei $n^{\circ}$ $128 / 2013$ determinou que, para os medicamentos biológicos, é essencial conhecer o nome do medicamento e o número de lote, pelo que o sistema de farmacovigilância deve estar preparado para recolher essa informação (artigo $167^{\circ}$ ), através dos profissionais de saúde (artigo $169^{\circ}$ ) e ainda dos doentes (artigo $\left.172^{\circ}\right)^{6}$

Este enquadramento encontra-se em vias de ser reconfigurado, através da utilização sistemática de dispositivos de segurança nas embalagens de medicamentos sujeitos a receita médica. ${ }^{32}$ Não estão abrangidos por esta disposição os medicamentos de terapia avançada. 


\section{DISCUSSÃO}

O quadro regulamentar do sistema de farmacovigilância aplica-se transversalmente a todos os medicamentos, muito embora se possa observar uma evolução no sentido da respetiva adequação a segmentos específicos como o dos medicamentos biológicos e biossimilares.

Importa agora observar a montante e a jusante de cada intervenção reguladora o grau de alinhamento com as demais disposições legais e operacionais. Aqui podem identificar-se três níveis de descontinuidade: (1) na transposição da legislação europeia para a nacional, (2) aplicação da legislação nacional no desenvolvimento dos documentos normativos e (3) articulação entre ambos e os sistemas operacionais.

O enquadramento básico e inicial das atividades de farmacovigilância é minimalista, ${ }^{4}$ não referindo qualquer especificidade quanto aos medicamentos biológicos. Distintamente um diploma posterior explicita que os medicamentos biológicos não são medicamentos genéricos, ${ }^{33}$ e subsequentemente, na transposição deste diploma, é referido que as notificações de reações adversas "identificam esses medicamentos através do nome e do número de lote."3

É também destacada a importância da farmacovigilância para este segmento de medicamentos, sendo referido que "sejam tomadas todas as medidas apropriadas para identificar todos os medicamentos biológicos receitados, distribuídos ou vendidos no seu território que sejam alvo de uma tal notificação, tendo na devida conta a denominação do medicamento, (...) e o número do lote"2 e subsequentemente em sede de transposição "as notificações destas suspeitas relativas a medicamentos biológicos receitados, distribuídos ou vendidos em Portugal, identificam esses medicamentos através do nome e do número de lote." 7

Relativamente aos impedimentos à introdução de medicamentos falsificados na cadeia de abastecimento legal não é explicitada qualquer determinação particular a observar no âmbito dos medicamentos biológicos e biossimilares. ${ }^{25}$ Contudo, na oitava alteração ao Decreto-lei n 176/2006 é observado, no âmbito das reações adversas, que "as notificações destas suspeitas relativas a medicamentos biológicos receitados, distribuídos ou vendidos em Portugal, identificam esses medicamentos através do nome e do número de lote."6 Por via de uma outra regulamentação, é reforçada a necessidade de adoção dos procedimentos normais e urgentes em consequência da emergência de questões de segurança. Contudo, não há outras menções específicas a serem consideradas para os medicamentos biológicos, em qualquer dos referidos eixos. ${ }^{5}$

Assim, tendo em conta todo o quadro regulamentar que vigora em Portugal podem identificar-se seis domínios que devem merecer particular atenção:

\section{Prescrição e dispensa em ambulatório, para os medica- mentos sujeitos a receita médica}

As normas emitidas pelo INFARMED e ACSS não mencionam as especificidades de prescrição e dispensa para os medicamentos biológicos. ${ }^{12}$ Detalhadamente, no que concerne aos termos de prescrição e para além da utilização da $\mathrm{DCl}$, está prevista a utilização do nome de marca, embora não se encontre referência explícita à utilização deste procedimento no âmbito da terapêutica com medicamentos biológicos. Tal constitui uma lacuna na regulamentação, que deve ser suprida com a revisão do texto. Neste texto, também se encontra omissa a referência ao número do lote e do titular de autorização de introdução no mercado para os biossimilares, bem como a informação que explicita se a prescrição se deve ao início ou a continuidade da terapêutica.

\section{Prescrição e dispensa em meio hospitalar, para os me- dicamentos de receita médica restrita}

Há um quadro regulamentar que integra os procedimentos e os instrumentos a serem utilizados. ${ }^{9,10}$ Contudo, observa-se que não se encontram adequados à terapêutica com medicamentos biológicos e biossimilares, pois os itens registados não permitem assegurar a cabal caracterização e rastreabilidade desses medicamentos. Há obrigatoriedade da identificação por intermédio da $\mathrm{DCl}$, dosagem, forma farmacêutica, posologia e duração da terapêutica. Não são assim consideradas informações como o nome de marca, o número de lote do medicamento ou a referência a início ou continuidade da terapêutica. Na mesma linha, é observado que o enquadramento legal específico para as condições de dispensa e utilização de medicamentos biológicos destinados à terapêutica antirreumática, ${ }^{11}$ bem como o que respeita à doença de Crohn e colite ulcerosa, ${ }^{13}$ não compreendem a informação referida supra, que assegura um pleno conhecimento das variáveis elucidativas do perfil de segurança associado à terapêutica com estes medicamentos.

\section{Impossibilidade de substituição do medicamento bioló- gico prescrito por denominação comercial}

Estão previstas três situações que determinam impossibilidade de substituição da terapêutica prescrita por denominação comercial, ${ }^{3,8}$ às quais se sugere a adição de uma outra alínea resultante da emissão das orientações da Comissão Nacional de Farmácia e Terapêutica. ${ }^{14}$ Segundo este documento, a opção terapêutica deve recair inicialmente sobre os medicamentos biossimilares, embora no caso da prescrição do medicamento de marca, se sugira a sua manutenção. Esta abordagem reforça assim o princípio da precaução. ${ }^{14}$

\section{Notificação de reações adversas}

O sistema de notificação deve considerar a possibilidade da interpermutabilidade e substituição como causa possível de reações adversas, tal como é apontado na orientação da Comissão Nacional de Farmácia e Terapêutica. Desta forma, deve estar preparado para incorporar informação associada a este domínio, para além daquela que se encontra focada no medicamento e que já se encontra contemplada por intermédio do Decreto-lei $n^{\circ} 128 / 2013$ de 5 de setembro. Neste domínio a magnitude da experiência clínica contribui decisivamente para a rigorosa identificação 
de efeitos adversos potenciais e subsequente notificação no âmbito do sistema de farmacovigilância.

\section{Comissão de análise à prescrição de agentes biológi- $\cos$}

Deve ser instituída a Comissão de Análise à Prescrição de Agentes Biológicos, ${ }^{12}$ definida pela norma 010/2014 da DGS. Nas suas atribuições, esta comissão deve proceder à análise da prescrição, e do ciclo terapêutico do doente submetido a terapêutica biológica, como via para acautelar a efetividade, a segurança e a adesão à terapêutica.

\section{Equacionar a expansão do quadro regulador}

Por último, deve ainda ser feita referência aos medicamentos de tipo proteico sintetizados por via química, que possuem as mesmas substâncias ativas antes obtidas por via biotecnológica. Uma vez que podem vir a ser considerados no contexto de interpermutabilidade e substituição, sugere-se que estes medicamentos e outros - como as terapias avançadas - sejam abrangidos pelas disposições aqui expostas.

\section{CONCLUSÃO}

A segurança associada aos medicamentos biológicos e biossimilares apresenta determinantes específicos que não encontram replicação em nenhum outro segmento do mercado farmacêutico. O desafio que se coloca ao sistema

\section{REFERÊNCIAS}

1. European Medicines Agency. Guideline on similar biological medicinal products. Committee for Medicinal Products for Human Use. London: EMA; 2014.

2. Parlamento Europeu. Diretiva 2010/84/UE do Parlamento Europeu e do Conselho de 15 de dezembro de 2010. Estrasburgo: Parlamento Europeu; 2010.

3. Ministério da Saúde. Decreto-lei no 176/2006. Lisboa: Imprensa Nacional Casa da Moeda; 2006.

4. Parlamento Europeu. Diretiva 2001/83/CE do Parlamento Europeu e do Conselho de 6 de novembro de 2001. Estrasburgo: Parlamento Europeu; 2001.

5. Parlamento Europeu. Diretiva 2012/26/UE do Parlamento Europeu e do Conselho de 25 de outubro de 2012. Estrasburgo: Parlamento Europeu; 2001.

6. Ministério da Saúde. Decreto-lei n 128/2013. Lisboa: Ministério da Saúde; 2013.

7. Parlamento Europeu. Regulamento (CE) n $n^{\circ} 726 / 2004$ do Parlamento Europeu e do Conselho de 31 de março de 2004. Estrasburgo: Parlamento Europeu; 2004.

8. Comissão Europeia. Regulamento de Execução $n^{\circ} 520 / 2012$ do Parlamento Europeu e do Conselho de 19 de junho de 2012. Bruxelas: Comissão Europeia; 2012.

9. Comissão Europeia. Regulamento Delegado (CE) n $357 / 2014$ da Comissão de 3 de fevereiro de 2014. Bruxelas: Comissão Europeia; 2014.

10. Parlamento Europeu. Regulamento Delegado (CE) $n^{\circ} 658 / 2014$ do Parlamento Europeu e do Conselho de 15 de maio de 2014. Estrasburgo: Parlamento Europeu; 2014.

11. Assembleia da República. Lei $n^{\circ}$ 51/2014. Lisboa: Assembleia da República; 2014.

12. Assembleia da República. Portaria 198/2016. Lisboa: Assembleia da República; 2016.

13. Ministério da Saúde. Decreto-lei $n^{\circ}$ 20/2013. Lisboa: Ministério da Saúde; 2013.

14. Ministério da Saúde. Portaria n²24/2015. Lisboa: Ministério da Saúde; 2015.

15. Ministério da Saúde. Despacho n 13382/2012. Lisboa: Ministério da é que funcione em sintonia e sincronia perfeitas entre os vários níveis de informação e institucionais. Assim, devem ser conduzidas as diligências necessárias ao ajustamento e concretização plena dos quadros legal e operacional relativos à terapêutica com medicamentos biológicos e biossimilares, com vista à promoção da consistência interna em ordem ao incremento da segurança da terapêutica com medicamentos biológicos e biossimilares.

\section{PROTECÇÃO DE PESSOAS E ANIMAIS}

Os autores declaram que os procedimentos seguidos estavam de acordo com os regulamentos estabelecidos pela Declaração de Helsínquia da Associação Médica Mundial.

\section{CONFIDENCIALIDADE DOS DADOS}

Os autores declaram ter seguido os protocolos do seu centro de trabalho acerca da publicação de dados.

\section{CONFLITOS DE INTERESSE}

Os autores declaram não existirem conflitos de interesse relativamente ao presente artigo.

\section{FONTES DE FINANCIAMENTO}

Os autores declaram ter recebido subsídio que contribuiu para a realização do trabalho da Roche Farmacêutica Química Lda.

Saúde; 2012

16. Infarmed. Procedimentos de cedência de medicamentos no ambulatório hospitalar. Circular Normativa n01/CD/2012.2012. Lisboa: Infarmed; 2012.

17. Ministério da Saúde. Portaria n48/2016. Lisboa: Ministério da Saúde; 2016.

18. Direção Geral da Saúde. Centro Prescritor de Agentes Biológicos. Circular Normativa n 010/2014. Lisboa: DGS; 2014.

19. Ministério da Saúde. Despacho 9767/2014. Lisboa: Ministério da Saúde; 2015.

20. Comissão Nacional de Farmácia e Terapêutica. Orientação. Medicamentos biossimilares. Lisboa: Infarmed; 2016

21. Comissão Europeia. Regulamento de Execução (UE) n 198/2013 da Comissão de 7 de março de 2013. Bruxelas: Comissão Europeia; 2013.

22. Parlamento Europeu. Regulamento (UE) $n^{\circ} 1027 / 2012$ do Parlamento Europeu e do Conselho de 25 de outubro de 2012. Estrasburgo: Parlamento Europeu; 2012.

23. Fonseca JE, Bernardes M, Canhão H, Santos MJ, Quintal A, Malcata A et al. Portuguese guidelines for the use of biological agents in rheumatoid arthritis-october 2011 update. Acta Reumatol Port. 2011;36:385-8.

24. Serviços Partilhados do Ministério da Saúde. Metodologia para pedido de dispensa de obrigatoriedade de aquisição ao abrigo dos acordos quadro da SPMS, EPE. Circular Normativa n 01/2015.Lisboa: Serviços Partilhados do Ministério da Saúde; 2015.

25. Parlamento Europeu. Regulamento (UE) $n^{\circ} 1235 / 2010$ do Parlamento Europeu e do Conselho de 15 de dezembro de 2010. Estrasburgo: Parlamento Europeu; 2010.

26. INFARMED - Autoridade Nacional do Medicamento e Produtos de Saúde. Formulário de notificação de reações adversas para profissionais de saúde. [acedido 2016 out 09]. Disponível em: http://www.infarmed. pt/portal/page/portal/INFARMED/MEDICAMENTOS_USO_HUMANO/ FARMACOVIGILANCIA/NOTIFICACAO_DE_RAM/Ficha $\% 20 \mathrm{de} \% 20$ notificacao\%20PS_setembro\%202014.pdf.

27. Parlamento Europeu. Regulamento (CE) no 1394/2007 do Parlamento Europeu e do Conselho de 13 de novembro de 2007 relativo a medicamentos de terapia avançada. Estrasburgo: Parlamento Europeu; 2007. 
28. Parlamento Europeu. Diretiva 2011/24/UE do Parlamento Europeu e do Conselho de 9 de março de 2011 relativa ao exercício dos direitos dos doentes em matéria de cuidados de saúde transfronteiriços. Estrasburgo: Parlamento Europeu; 2011.

29. Ministério da Saúde. Despacho n 11042-F/2014. Lisboa: Ministério da Saúde; 2014.

30. Assembleia da República. Lei $n^{\circ}$ 52/2014. Lisboa: Assembleia da República; 2014

31. Parlamento Europeu. Diretiva 2011/62/UE do Parlamento Europeu e do
Conselho de 8 de junho de 2011. Estrasburgo: Parlamento Europeu; 2011.

32. Comissão Europeia. Regulamento Delegado (UE) 2016/161 da Comissão de 2 de outubro de 2015. Bruxelas: Comissão Europeia; 2016.

33. Parlamento Europeu. Diretiva 2004/27/CE do Parlamento Europeu e do Conselho de 31 de março de 2004. Estrasburgo: Parlamento Europeu; 2004. 